\title{
Identification of CD318 (CDCP1) as novel prognostic marker in AML
}

\author{
Jonas S. Heitmann ${ }^{1,2}$ • Ilona Hagelstein ${ }^{1,2}$ • Clemens Hinterleitner ${ }^{2,3}$ • Malte Roerden ${ }^{4}$. Gundram Jung ${ }^{5}$. \\ Helmut R. Salih ${ }^{1,2} \cdot$ Melanie Märklin $^{1,2}$ (D) Joseph Kauer ${ }^{5}$
}

Received: 24 September 2019 / Accepted: 13 January 2020 / Published online: 21 January 2020

(C) The Author(s) 2020

\begin{abstract}
Genetic and morphological markers are well-established prognostic factors in acute myeloid leukemia (AML). However, further reliable markers are urgently needed to improve risk stratification in AML. CD318 (CDCP1) is a transmembrane protein which in solid tumors promotes formation of metastasis and correlates with poor survival. Despite its broad expression on hematological precursor cells, its prognostic significance in hematological malignancies so far remains unclear. Here, we evaluated the role of CD318 as novel prognostic marker in AML by immunophenotyping of leukemic blasts. Flow cytometric evaluation of CD318 on leukemic cells in 70 AML patients revealed a substantial expression in 40/70 (57\%) of all cases. CD318 surface levels were significantly correlated with overall survival in patients receiving anthracycline-based induction therapy or best available alternative therapy. Using receiver-operating characteristics, we established a cut-off value to define CD318 ${ }^{\mathrm{lo}}$ and $\mathrm{CD} 318^{\mathrm{hi}}$ expression in both cohorts. Notably, high CD318 expression correlated inversely as prognostic marker in both treatment cohorts: as poor prognostic marker in patients receiving intense therapy, whereas upon palliative care it correlated with better outcome. In conclusion, FACS-based determination of CD318 expression may serve as novel prognostic factor depending on implemented therapy in AML patients.
\end{abstract}

Keywords AML $\cdot \mathrm{CD} 318 \cdot \mathrm{CDCP} 1 \cdot$ Prognosis $\cdot$ Risk stratification

\section{Introduction}

Acute myeloid leukemia (AML) is a disease with high mortality and variable prognosis [1,2]. Well-established prognostic factors are cytogenetic aberrations such as $\mathrm{t}(8 ; 21)$, inv(16), and $\mathrm{t}(15 ; 17)$ as well as mutated IDH1/2, NPM1, and FLT3 genes [3]. Immunophenotyping via flow cytometry comprises an additional fast technique to predict outcome in AML, although only few markers are yet established as prognostic factors in clinical

Electronic supplementary material The online version of this article (https://doi.org/10.1007/s00277-020-03907-9) contains supplementary material, which is available to authorized users.

Melanie Märklin

melanie.maerklin@med.uni-tuebingen.de

1 Clinical Collaboration Unit Translational Immunology, German Cancer Consortium (DKTK), Department of Internal Medicine, University Hospital Tübingen, Tübingen, Germany

2 DFG Cluster of Excellence 2180 'Image-guided and Functional Instructed Tumor Therapy’ (IFIT), University of Tübingen, Tübingen, Germany routine diagnosis, despite the fact that new and rapidly available markers are needed to improve the treatment decisions in AML patients. This is even more since therapy in AML patients must be initiated immediately after diagnosis [1].

CD318 (CUB domain containing protein-1, CDCP1) is a highly glycosylated single pass transmembrane protein expressed on mesenchymal and neural stem cells and fibroblasts and hematopoietic progenitors [4-7]. CD318 overexpression has been recently correlated with poor overall survival (OS) in colon, breast,

3 Department of Internal Medicine VIII, University Hospital Tübingen, Tübingen, Germany

4 University Hospital Tübingen, Department of Oncology, Haematology and Immunology, Tübingen, Germany

5 Department of Immunology, German Cancer Consortium (DKTK) and German Cancer Research Center (DKFZ), Interfaculty Institute for Cell Biology, University of Tübingen, Partner Site Tübingen, Tübingen, Germany 
lung, renal, hepatocellular, and pancreatic carcinoma [8-14], possibly due to its role in metastasis formation via interaction with integrins and anti-apoptotic signaling via Akt [15-18].

In hematopoietic cells, CD318 has been identified as stem cell marker for both benign and malignant progenitor cells. CD318 ${ }^{+}$ bone marrow or cord blood-derived cells have been shown to be capable to initiate multi-lineage hematopoiesis in vitro and in vivo [6]. Of AML blasts, pronounced CD318 expression has been observed on the immature $\mathrm{CD} 34^{+} \mathrm{CD} 133^{+}$leukemic cells subset implicated to be enriched for leukemic stem cells [5, 6]. However, the impact of CD318 on survival in hematological malignancies has so far not been analyzed.

In this study, we investigated the role of flow cytometric analysis of AML blasts $(n=70)$ and correlated CD318 expression with disease outcome.

\section{Materials \& methods}

\section{Patient samples}

Peripheral blood samples of 70 patients with AML were drawn at primary diagnosis. Peripheral blood mononuclear cells (PBMC) of patients were isolated by density gradient centrifugation and used for flow cytometry. Median observational time for all patients was 554 days $(95 \%$ CI of mean 409-698 days). Diagnosis and classification of AML samples relied on morphology and cytochemistry of bone marrow according to the French-American-British (FAB) classification $[19,20]$. Cytogenetic analyses were performed at the University of Ulm with standard methods.

\section{Flow cytometry}

PBMC of AML patients were treated with human IgG (Sigma-Aldrich, St. Louis, MO) prior to the staining in order to minimize Fcy receptor binding, then washed and followed by adding the unconjugated CD318 mAb (clone CUB1, Biolegend, San Diego, CA) or the isotype control at $1 \mu \mathrm{g} / \mathrm{ml}$, followed by species-specific PE-conjugated antibodies (1:100). Then, AML blasts were identified according to the immunophenotype obtained at diagnosis by staining for CD33, CD34, CD38, CD117, and CD13. Dead cells were excluded based on 7-AAD (BioLegend) positivity. Fluorescence-conjugates (CD13, CD33, CD34, CD38, and CD117, BioLegend) were used in 1:100-1:200 dilutions. Specific fluorescence indices (SFIs) were calculated by dividing median fluorescence obtained with anti-CD318 mAb by median fluorescence obtained with the IgG2b isotype control. Positive expression was defined as SFI $\geq 1.5$. Measurements were conducted using a LSR Fortessa or a FACSCanto II (BD Biosciences, Heidelberg, Germany), and data analysis was performed with FlowJo_V10 software (FlowJo LCC,
Ashland, OR). Graphs were created using GraphPad Prism 8.1.0 (GraphPad Software, San Diego, CA).

\section{Statistical analysis}

Data are shown as mean \pm SD and boxplots including mean and 25 and $75 \%$ quartiles as well as $\min / \max$ or Tukey whiskers. To compare individual groups, the 2-tailed unpaired students $t$ test, Mann-Whitney-/Kruskal-Wallis-test, Chi square test, or Fisher's exact test were used. Distribution of overall survival (OS) was calculated using the Kaplan-Meier method. Log-rank test was performed to compare survival between groups. For predictive cut-off value estimation, we sub-grouped CD318 SFI with respect to corresponding OS times and by employed treatment. Receiveroperating characteristics (ROC) analysis was performed using JMP® Pro (SAS Institute Inc., Version 14.2), and value of highest Youden index was used as cut-off. Cut-off values enabled further separation of cases with better or worse prognosis, as shown in Kaplan-Meier analysis. Statistical analyses were conducted using JMP® Pro and GraphPad Prism 8.1.0 software. $P$ values of $<$ 0.05 were considered statistically significant.

\section{Results}

\section{Clinical features of AML patients}

For the analysis of CDCP1 expression, we analyzed primary AML samples of 70 patients. The clinical characteristics of the patients are given in Table 1 and Supplementary Table 1. Twenty patients presented with undifferentiated leukemia (M0: $n=6$, M1: $n=14), 17$ with immature granulocytic leukemia (M2: $n=14, \mathrm{M} 3: n=5$ ), and 21 with monocytic leukemia (M4: $n=$ 12, M5: $n=9$ ); nine patients had erythroleukemia (M6). In 52 patients, primary AML was diagnosed, and in 18 patients secondary AML was diagnosed. The age ranged from 21 to 85 years (with a median of 64 years) with a male:female ratio of 1:1.26. With regard to cytogenetics, 33 patients presented with normal karyotype, 24 with $<3$ aberrations, and seven with complex karyotype. In detail, 5 cases with $t(15 ; 17), 3$ with inv(16), as well as 3 with $\mathrm{t}(9 ; 11)$ were included. FLT3-TKD mutations were detected in 6 patients, while a higher number $(n=25)$ presented with FLT3-ITD mutation, 15 of whom displayed a high FLT3ITD ratio. NPM1 mutations were detected in 25 patients, while CCAAT/enhancer binding protein $\alpha$ (CEBPA) mutations were seen in 5 patients, and IDH2 mutations in 4 patients. Mutational status of TP53 was not assessed. On the basis of cytogenetics, patients were categorized according to National Comprehensive Cancer Network (NCCN) risk score [21]. Patient numbers in the favorable and intermediate risk group were 24 , whereas 17 cases presented with adverse risk.

Induction therapy was applied to 42 patients; the remaining patients $(n=28)$ were treated with other approved therapies 
Table 1 Patients' characteristics

Number of patients $(\%)$

\begin{tabular}{|c|c|}
\hline \multicolumn{2}{|l|}{ Sex } \\
\hline Male & $31(44)$ \\
\hline Female & $39(56)$ \\
\hline Median age (years) & 64 (range 21-85) \\
\hline \multicolumn{2}{|l|}{ FAB classification } \\
\hline M0 & $6(9)$ \\
\hline M1 & $14(20)$ \\
\hline M2 & $14(20)$ \\
\hline M3 & $5(7)$ \\
\hline M4 & $12(17)$ \\
\hline M5 & $9(13)$ \\
\hline M6 & $9(13)$ \\
\hline Not classified & $1(1)$ \\
\hline Unfavorable FAB & $15(22)$ \\
\hline \multicolumn{2}{|l|}{ WHO classification } \\
\hline AML with recurrent genetic abnormalities & $37(53)$ \\
\hline AML with myelodysplasia-related changes & $12(17)$ \\
\hline Therapy-related myeloid neoplasms & $3(4)$ \\
\hline Myeloid neoplasms with germline predisposition & $0(0)$ \\
\hline AML, not otherwise specified & $18(26)$ \\
\hline \multicolumn{2}{|l|}{ Primary/secondary AML } \\
\hline Primary & $52(74)$ \\
\hline Secondary & $18(26)$ \\
\hline \multicolumn{2}{|l|}{ Blood count } \\
\hline WBC (G/L) & 61 (range 5-448) \\
\hline $\mathrm{Hb}(\mathrm{g} / \mathrm{dl})$ & 8 (range $4-13$ ) \\
\hline Plt (G/L) & 41 (range 6-243) \\
\hline \multicolumn{2}{|l|}{ NCCN risk score distribution } \\
\hline Favorable & $24(34.5)$ \\
\hline Intermediate & $24(34.5)$ \\
\hline Poor & $17(24)$ \\
\hline Not classified & $5(7)$ \\
\hline Complete response after induction therapy ${ }^{\pi}$ & $27(66)$ \\
\hline
\end{tabular}

$F A B$, French-American-British; WBC, white blood count; $H b$, hemoglobin; Plt, thrombocytes; $N C C N$, National Comprehensive Cancer Network $\pi$ only patients receiving anthracycline-based induction therapy, response assessment on day 25-35 after induction (CR, CRi)

(e.g., hydroxyurea, hypomethylating agents) or best supportive care. Response to chemotherapy was defined according to the European Leukemia Network (ELN) definition [22]. Complete response (CR) was defined as presentation with normocellular bone marrow containing $<5 \%$ blasts and neutrophilic granulocytes in peripheral blood $(\mathrm{PB})$ recovered to $1500 / \mu \mathrm{l}$ and platelets to $100,000 / \mu \mathrm{l}$. In contrast, complete remission with incomplete blood count recovery (CRi) lacked hematologic recovery in $\mathrm{PB}$ with neutrophil counts below $1000 / \mu 1$ or platelets below $100,000 / \mu 1$. CR after anthracycline-based induction therapy was reached in $66 \%$ of treated patients.
Prognostic evaluation of CD318 expression in AML

Leukemic blasts were analyzed for CD318 expression by flow cytometry as exemplified in Fig. 1a. Considering an SFI level of 1.5 a as margin for positivity, $57 \%$ of AML patients expressed relevant CD318 levels. Among all AML cases, highly variable surface levels of CD318 ranging from 1.5 to SFI levels of 66.8 were observed. In addition, the percentage of positive cells varied substantially ranging from 0 to almost $100 \%$ of the leukemic blasts (Fig. 1b).

Distribution of CD318 surface levels differed among FAB subclasses, with a tendency to lower expression in 
a
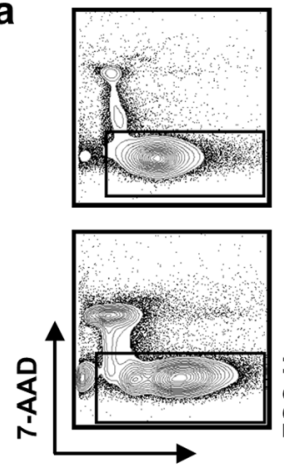

FSC-A
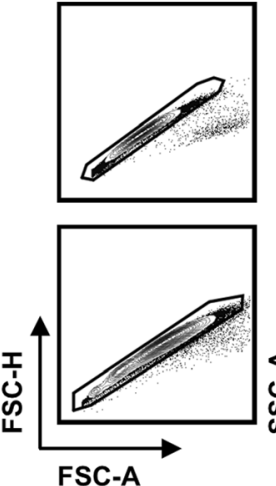
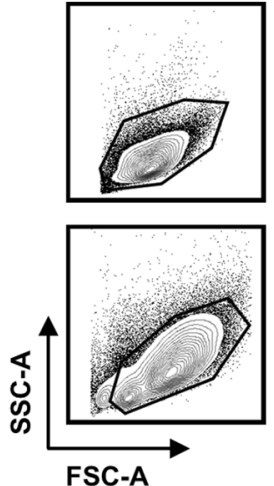

FSC-A
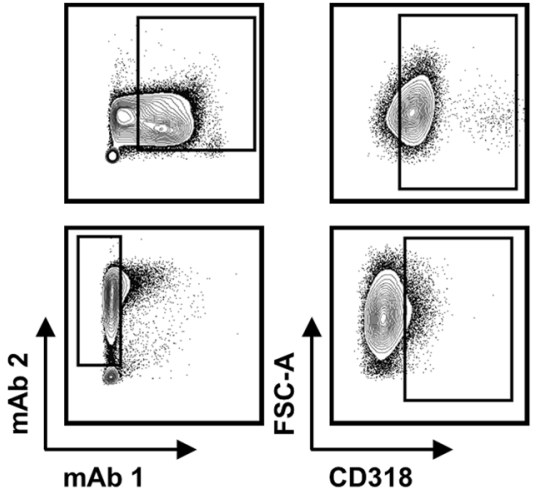

C

b
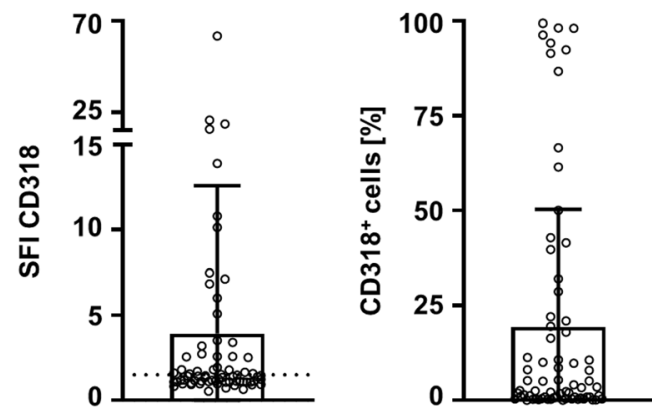

d

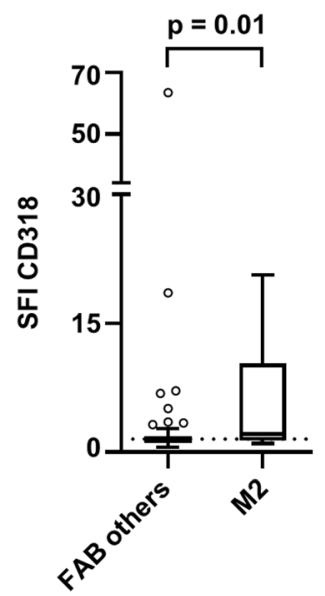

e

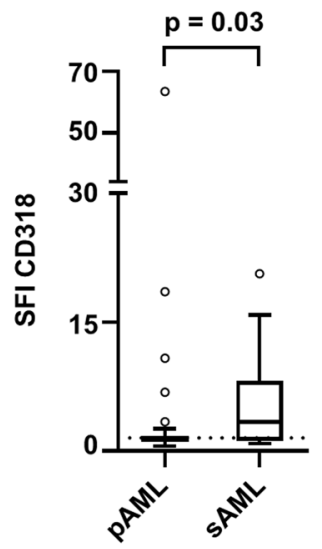

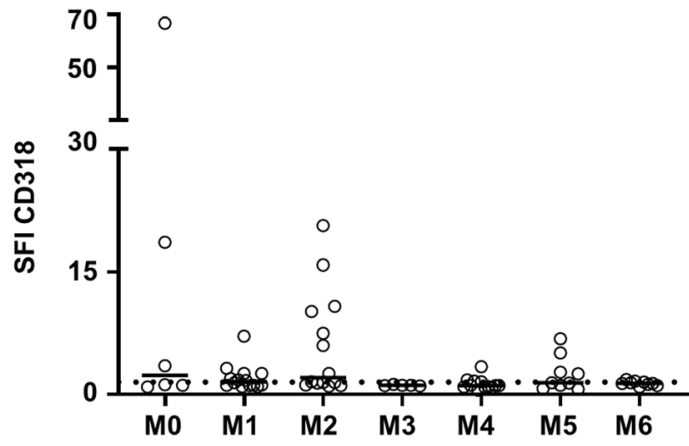

f

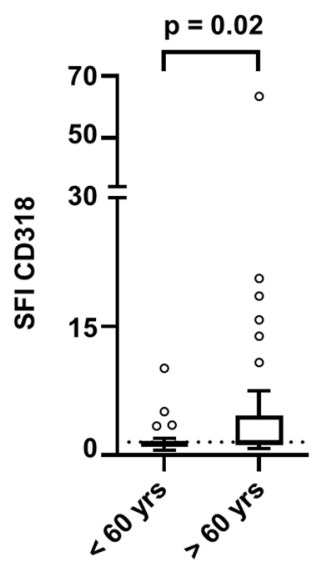

Fig. 1 CD318 expression on hematopoietic cells and association with clinical parameters. CD318 expression was analyzed on hematopoietic cells by flow cytometry. SFI levels above 1.5 were considered as positive expression (dotted line). a Gating strategy for two exemplary AML samples: viable (7-AAD-), singlets, mononuclear cells, blast marker (AML 1: CD13/CD33, AML 2: CD33/CD14-), and CD318 expression. b CD318 expression on blasts of AML patients $(n=70)$ are depicted as SFI levels and percentage of CD318 positive blasts (boxplots with min/

mature leukemia (FAB M4/5) and higher expression in immature leukemia (Fig. 1c). In comparison to all other FAB subtypes $(n=56)$, cases with FAB M2 $(n=14)$ expressed the highest CD318 levels $(p=0.01)$ (Fig. 1d).

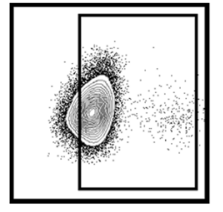

AML 1

AML 2

max whiskers). $\mathbf{c}-\mathbf{e}$ CD318 SFI levels according to the different FAB classifications (single values, median) (c), FAB others vs. FAB M2 (boxplots with Tukey whiskers; Mann-Whitney test) (d), primary (pAML) vs. secondary (sAML) AML (boxplots with Tukey whiskers; Mann-Whitney test) (e), and according to age $<60$ and $>60$ years (boxplots with Tukey whiskers; Mann-Whitney test) (f) are shown. g Distribution of CD318 expression (SFI) throughout NCCN risk group (boxplots with Tukey whiskers; Kruskal-Wallis test)

CD318 expression further varied between primary (pAML) and secondary AML (sAML) with a significantly higher expression in the latter (SFI mean 3.3 vs. 5.7; $p=0.025$ ) (Fig. 1e). In line, classification using WHO 
criteria revealed a significantly higher CD318 SFI in "AML with myelodysplasia-related changes" compared with "AML with recurrent genetic abnormalities" (data not shown). Furthermore, on leukemic blasts of patients older than 60 years, CD318 expression was significantly enhanced in comparison to younger patients $(p=0.02)$ (Fig. 1f). When grouped according to the NCCN risk classification, patients with intermediate risk expressed higher levels of CD318 than favorable risk patients $(p=0.02)$, whereas this was not veritable in comparison to poor risk $(p=0.2)$ (Fig. $1 \mathrm{~g})$.

\section{Distinct CD318 expression profile on AML blasts of patients with poor prognosis}

Since CD318 expression varied among AML patient cells, for subsequent analysis, predicted cut-off values were estimated by ROC analysis. An SFI of 1.8 (AUC 0.56, 95\% CI 0.42 0.7) separated all AML patients in CD318 high $\left(C D 318^{\text {hi }}\right)$ and low $\left(\mathrm{CD} 318^{\mathrm{lo}}\right)$ expressing cases. In our cohort including all therapy strategies, this estimated cut-off value and thereby grouping of AML patients did not reveal any difference on OS (hazard ratio (HR) $0.83 ; p=0.61$ ) (Fig. 2a). However,
Fig. 2 Impact of CD318 expression on clinical outcome. a Overall survival (OS) in AML patients according to $\mathrm{CD} 318^{\text {lo }}$ and CD $318^{\text {hi }}$ expression in Kaplan-Meier analysis. b Overall survival in patients without intense therapy according to $\mathrm{CD} 318^{\text {lo }}$ and $\mathrm{CD} 318^{\text {hi }}$ expression in Kaplan-Meier analysis. Mean OS was reached in $\mathrm{CD} 318^{\mathrm{lo}}$ (dotted line) and CD31 hi $^{\text {hi }}$ (continuous line) after 14 or 194.5 days, respectively, and differed significantly (log-rank test). c Overall survival in patients receiving hypomethylating agents according to $\mathrm{CD} 318^{\mathrm{lo}}$ and CD318 $8^{\text {hi }}$ expression in KaplanMeier analysis. d Overall survival in patients receiving anthracyclinbased induction therapy (ABIT) according to $\mathrm{CD} 318^{\mathrm{lo}}$ and CD318 ${ }^{\text {hi }}$ expression in KaplanMeier analysis. Mean OS was only reached in $\mathrm{CD} 318^{\mathrm{hi}}$ after 572 days (dotted line; log-rank test). e Progression-free survival (PFS) according to CD318 ${ }^{\text {lo }}$ and CD318 ${ }^{\text {hi }}$ expression in KaplanMeier analysis. In CD318 ${ }^{\text {hi }}$, the mean PFS was 513 days (dotted line; log-rank test) and could not be reached in $\mathrm{CD} 318^{\text {lo }}$ (continuous line)
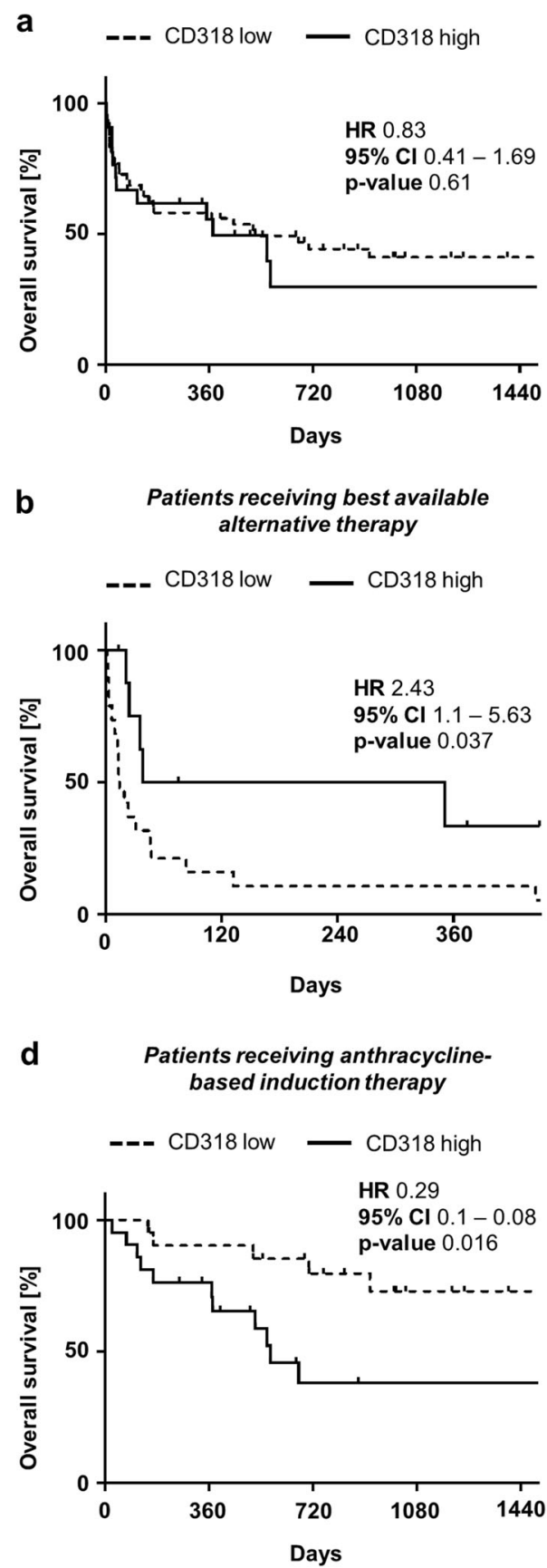
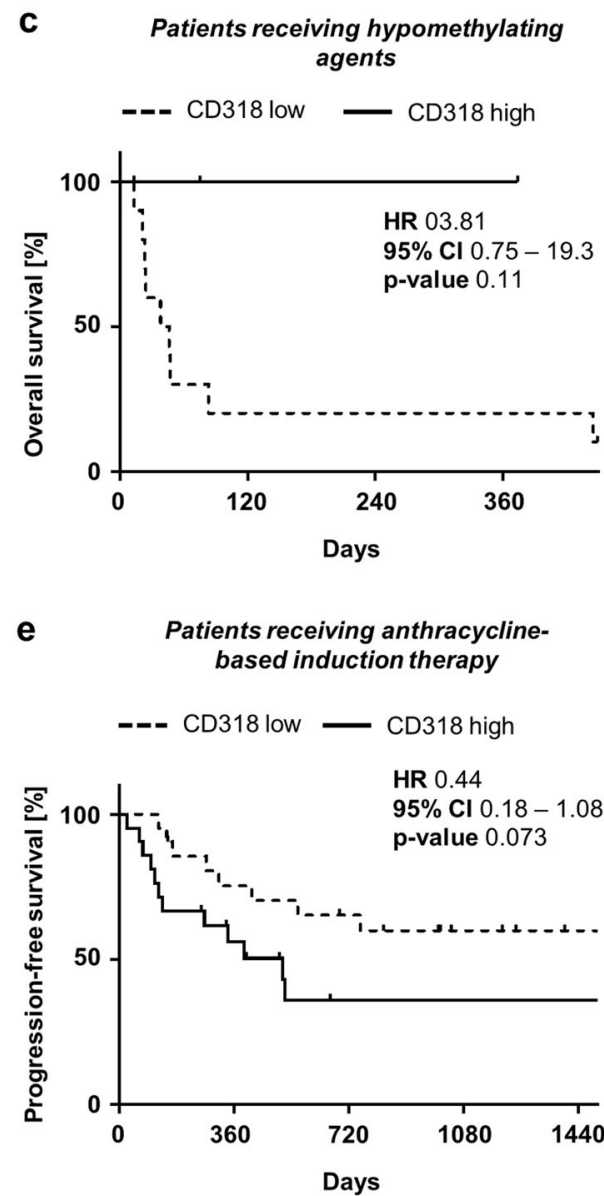
upon separating patients according to their applied therapy (anthracycline-based induction therapy vs. best available alternative treatment), a significant correlation of CD318 surface levels on AML blasts with prognosis was observed.

Considering clinical characteristics of patients, separation by a cut-off value of SFI 3.2 (AUC 0.82, 95\% CI 0.6-1.0) for patients receiving best available alternative therapy identified a trend to more cases of secondary AML in CD31 ${ }^{\text {hi }}$ patients, however without reaching statistical significance $(p=0.052)$. When patients were grouped according to NCCN risk score, we detected a significantly higher percentage of intermediate and poor risk patients in $\mathrm{CD} 318^{\text {hi }}$ cases $(p=0.03)$. Interestingly, white blood count (WBC) was significantly increased in CD318 ${ }^{\mathrm{lo}} \mathrm{AML}$ patients $(p=0.0006)$. Furthermore, the rate of NPM1 mutation was significantly higher in $\mathrm{CD} 318^{\mathrm{lo}}$ AML patients $(p=0.03$ ) (Table 2 and Supplementary Table 2).

In $\mathrm{CD} 318^{\mathrm{lo}}$ patients receiving alternative therapy, OS was significantly worse when compared with $\mathrm{CD} 318^{\text {hi }}$ cases (HR 2.43; $p=0.037$ ) (Fig. 2a). These findings were supported by analysis of the subgroup of AML patients receiving hypomethylating agents $(n=13)$, which showed a clear trend to better OS in CD318 ${ }^{\text {hi }}$ cases, however without reaching statistical significance (HR 3.81; $p=0.11$ ) (Fig. 2c).

Subsequently, a cut-off value was estimated using ROC analysis in patients receiving anthracycline-based induction therapy (SFI 1.17, AUC 0.63, 95\% CI 0.45-0.81). In this patient group, comparison of $\mathrm{CD} 318^{\mathrm{lo}}$ and $\mathrm{CD} 318^{\text {hi }}$ cases revealed no statistical significance for any clinical parameter except for a higher rate of IDH2 mutations in CD318 ${ }^{\text {hi }}$ cases $(p=0.04)$ (Table 2 and Supplementary Table 2).

However, CD $318^{\text {hi }}$ cases receiving anthracycline-based induction therapy displayed a significantly lower OS in comparison to $\mathrm{CD} 318^{\text {lo }}$ (HR 0.29; $p=0.016$ ) (Fig. 2d). A similar trend was observed for progression-free survival (PFS), however without reaching statistical significance in our cohort (HR 0.44; $p=0.073$ ) (Fig. 2e).

To confirm these results in patients receiving anthracyclinebased induction therapy, multivariate analysis including age $(<$ 60 vs. $\geq 60$ years), WBC, primary/secondary AML, risk profile according NCCN, and CD318 expression was conducted. A HR of 4.11 was calculated for $\mathrm{CD} 318^{\text {hi }}$ which attributes the strongest correlation of all markers to CD318 expression $(p=0.02)$. As expected, poor NCCN risk cases showed a significantly decreased OS $(p=0.03)$. All other parameters showed no significant impact on OS (Fig. 3a).

In an alternative approach (depicted as model II), an extended multivariate analysis for patients receiving anthracycline-based induction therapy including age $(<60$ vs. $\geq 60$ years), WBC, primary/ secondary AML, risk profile according NCCN, karyotype, FLT3-ITD mutation status, NPM1 mutation status, CEBPA mutation status, and CD318 expression was performed. Eight patients were excluded due to unavailability of the cytogenetic parameters. A HR of 303 for $\mathrm{CD} 318^{\mathrm{hi}}$ underlines the strong correlation between CD $318^{\text {hi }}$ expression and poor survival $(p=0.002)$. FLT3ITD positive cases showed significantly decreased OS $(p=$ 0.01 ), which is in line with the literature [1]. Cases of secondary AML showed increased OS $(p=0.03)$. All other parameters showed no significant impact on OS (Fig. 3b).

\section{Discussion}

In this study, we analyzed CD318 expression on peripheral blasts of 70 AML patients and observed substantial CD318 expression in $57 \%$ of all patients. So far, only few publications have reported on the expression of $\mathrm{CD} 318$ in hematological malignancies [5, 6]. CD318 mRNA as well as surface expression was detected on the K562 cell line, but not in Jurkat (T cell leukemia) and Raji (Burkitt lymphoma) cell lines [23]. Bühring et al. implemented flow cytometry using the antibody CUB1 and showed surface expression on 7/11 AML patients [5]. The observed expression of CD318 in 57\% of the analyzed AML cases in our cohort was comparable to that reported by Bühring et al.

Beside expression in various cancer entities, functionally relevant expression of $\mathrm{CD} 318$ was described on hematopoietic, neural, and mesenchymal stem cells $[5,6]$. With regard to hematopoiesis, $\mathrm{CD} 34^{+} \mathrm{CD} 38^{-} \mathrm{CD} 318^{+}$cells comprise a group of myeloid progenitor cells [5], and $\mathrm{CD} 318^{+}$bone marrow- or cord blood-derived cells reportedly are particularly capable of forming multi-lineage hematopoiesis in vitro as well as in a xenograft model $[6,24]$. In contrast to hematopoietic progenitor cells, the molecule is absent on mature lymphocytes, monocytes, granulocytes, erythrocytes, and platelets [6]. This suggests a role of CD318 as marker of myeloid progenitors in both benign and malignant hematological cells. Interestingly, our findings point in a similar direction, since undifferentiated subtypes of AML showed a higher CD318 expression in comparison to differentiated leukemic blasts.

CD318 expression has also been associated with the presence of genetic aberrations. For example, in lung carcinoma, CD318 surface levels correlate with Ras mutations [18]. In our study analyzing patients with AML, no association between genetic aberrations or mutations was observed, although we detected higher CD318 expression in secondary AML and patients with age above 60 years.

Besides other mechanisms, CD318 expression is induced via hypoxia-inducible factor (HIF)-2 alpha [25]. HIF-2 alpha protects hematopoietic progenitors as well as AML cells from apoptosis due to endoplasmic reticulum stress [26]. Moreover, it promotes AML progression in mouse models, but HIF-2 alpha is not established as prognostic marker in AML [27]. Further studies demonstrated an accelerated growth of CD318transfected MCF-7 cells in mice compared with mocktransfected controls [28]. In addition, CD318 surface overexpression is correlated with poor overall survival in colon, breast, lung, 
Table 2 Distribution of patients' characteristics according to CD318 ${ }^{\text {hi }}$ and CD318 ${ }^{\text {lo }}$

\begin{tabular}{|c|c|c|c|c|c|c|}
\hline & \multicolumn{3}{|c|}{ Best available alternative therapy } & \multicolumn{3}{|c|}{ Anthracycline-based induction therapy } \\
\hline & \multicolumn{2}{|c|}{ Number of patients (\%) } & \multirow[b]{2}{*}{$p$ value } & \multicolumn{2}{|l|}{ Number of patients (\%) } & \multirow[b]{2}{*}{$\begin{array}{l}p \\
\text { value }\end{array}$} \\
\hline & $\begin{array}{l}\mathrm{CD} 318^{\mathrm{lo}}(\mathrm{SFI}<3.2) \\
n=19\end{array}$ & $\begin{array}{l}\mathrm{CD} 318^{\mathrm{hi}} \\
(\mathrm{SFI} \geq 3.2) n=9\end{array}$ & & $\begin{array}{l}\mathrm{CD} 318^{\mathrm{lo}}(\mathrm{SFI}<1.17) \\
n=21\end{array}$ & $\begin{array}{l}\mathrm{CD} 318^{\mathrm{hi}}(\mathrm{SFI} \geq 1.17) \\
n=21\end{array}$ & \\
\hline \multicolumn{7}{|l|}{ Sex } \\
\hline Male & $13(68.5)$ & $5(55.5)$ & $0.51^{\lrcorner}$ & $9(43)$ & $12(57)$ & $0.35^{\lrcorner}$ \\
\hline Female & $6(31.5)$ & $4(44.5)$ & & $12(57)$ & $9(435)$ & \\
\hline Median age (years) & 73 (range 26-83) & 78 (range 58-85) & $0.15^{\dagger}$ & 47 (range $23-73$ ) & 58 (range $21-74$ ) & $0.27^{\dagger}$ \\
\hline FAB classification & & & $0.19^{*}$ & & & $0.15^{*}$ \\
\hline M0 & $2(10.5)$ & $3(37.5)$ & & $1(5)$ & $0(0)$ & \\
\hline M1 & $4(21)$ & $2(25)$ & & $3(14)$ & $5(24)$ & \\
\hline M2 & $2(10.5)$ & $2(25)$ & & $3(14)$ & $7(33)$ & \\
\hline M3 & $0(0)$ & $0(0)$ & & $4(19)$ & $1(4.5)$ & \\
\hline M4 & $2(10.5)$ & $0(0)$ & & $7(33)$ & $3(14)$ & \\
\hline M5 & $5(26.5)$ & $1(12.5)$ & & $2(9)$ & $1(4.5)$ & \\
\hline M6 & $4(21)$ & $0(0)$ & & $1(5)$ & $4(20)$ & \\
\hline Unfavorable FAB & $6(32.5)$ & $3(37.5)$ & $0.77^{\lrcorner}$ & $2(9.5)$ & $4(19)$ & $0.37^{\lrcorner}$ \\
\hline WHO classification & & & $0.13^{\ddagger}$ & & & $0.68^{*}$ \\
\hline $\begin{array}{l}\text { AML with recurrent genetic } \\
\text { abnormalities }\end{array}$ & $9(48)$ & $1(11)$ & & $15(71)$ & $12(57)$ & \\
\hline $\begin{array}{l}\text { AML with myelodysplasia-related } \\
\text { changes }\end{array}$ & $5(26)$ & $3(33.5)$ & & $1(5)$ & $3(14)$ & \\
\hline Therapy-related myeloid neoplasms & $0(7)$ & $1(11)$ & & $1(5)$ & $1(5)$ & \\
\hline $\begin{array}{l}\text { Myeloid neoplasms with germline } \\
\text { predisposition }\end{array}$ & $0(0)$ & $0(0)$ & & $0(0)$ & $0(0)$ & \\
\hline AML, not otherwise specified & $5(26)$ & $4(44.5)$ & & $4(19)$ & $5(24)$ & \\
\hline \multicolumn{7}{|l|}{ Primary/secondary AML } \\
\hline Primary & $14(74)$ & $5(33)$ & $0.052^{\lrcorner}$ & $19(90.5)$ & $16(76)$ & $0.21^{\lrcorner}$ \\
\hline Secondary & $3(26)$ & $6(67)$ & & $2(9.5)$ & $5(24)$ & \\
\hline \multicolumn{7}{|l|}{ Blood count } \\
\hline WBC (G/L) & 137.4 & 32.5 & $0.0006^{\dagger}$ & 79.9 & 112.7 & $0.25^{\dagger}$ \\
\hline $\mathrm{Hb}(\mathrm{g} / \mathrm{dl})$ & 8.6 & 8.8 & $0.69^{\dagger}$ & 8.2 & 8.2 & $0.98^{\dagger}$ \\
\hline Plt (G/L) & 66.7 & 66.2 & $0.98^{\dagger}$ & 51.5 & 75.7 & $0.15^{\dagger}$ \\
\hline NCCN risk score distribution & & & $0.03^{\star}$ & & & $0.28^{*}$ \\
\hline Favorable & $7(37)$ & $0(0)$ & & $11(52.5)$ & $6(29)$ & \\
\hline Intermediate & $6(31.5)$ & $6(67)$ & & $5(24)$ & $7(33)$ & \\
\hline Poor & $4(21)$ & $3(33)$ & & $3(14)$ & $7(33)$ & \\
\hline Not classified & $2(10.5)$ & $0(0)$ & & $2(9.5)$ & $1(5)$ & \\
\hline $\begin{array}{l}\text { Complete response after induction } \\
\text { therapy }{ }^{\pi}\end{array}$ & $\mathrm{n} / \mathrm{a}$ & $\mathrm{n} / \mathrm{a}$ & $\mathrm{n} / \mathrm{a}$ & $15(75)$ & $12(57)$ & $0.23^{\lrcorner}$ \\
\hline
\end{tabular}

$F A B$, French-American-British; $W B C$, white blood count; $H b$, hemoglobin; Plt, thrombocytes; $N C C N$, National Comprehensive Cancer Network

$\pi$ only patients receiving anthracycline-based induction therapy, response assessment: on day 25-35 after induction (CR, CRi). Statistical analysis with

\lrcorner Fisher's exact test, ${ }^{\dagger}$ Pearson-Chi square and ${ }^{\dagger}$ students $t$ test

renal, hepatocellular, and pancreatic carcinoma [8-14]. This has been attributed to the enhanced formation of metastasis via CD318 by its interaction with activated integrin $\beta-1$ during stromal invasion and transendothelial migration [15]. Metastasis promotion by CD318 includes cleavage of the membrane-bound protein by serine proteases and subsequent phosphorylation by
Src kinases [16]. Finally, Akt activation inhibits PARP1mediated apoptosis and promotes survival of tumor cells during extravasation and tissue invasion [17]. In addition, achievement of CR after intense therapy was not significantly different between CD318 ${ }^{\text {lo }}$ and CD318 ${ }^{\text {hi }}$ patients, as one would expect due to anti-apoptotic signaling via CD318. 
Fig. 3 Multivariate analysis for survival in patients receiving anthracycline-based induction therapy. a Model I: all patients receiving anthracycline-based induction therapy $(n=42)$. b Model II: patients receiving anthracycline-based induction therapy with known cytogenetic parameters $(n=34)$. NCCN National Comprehensive Cancer Network; WBC white blood count; ${ }^{ \pm}$reference group, dotted line: $\mathrm{HR}=1$

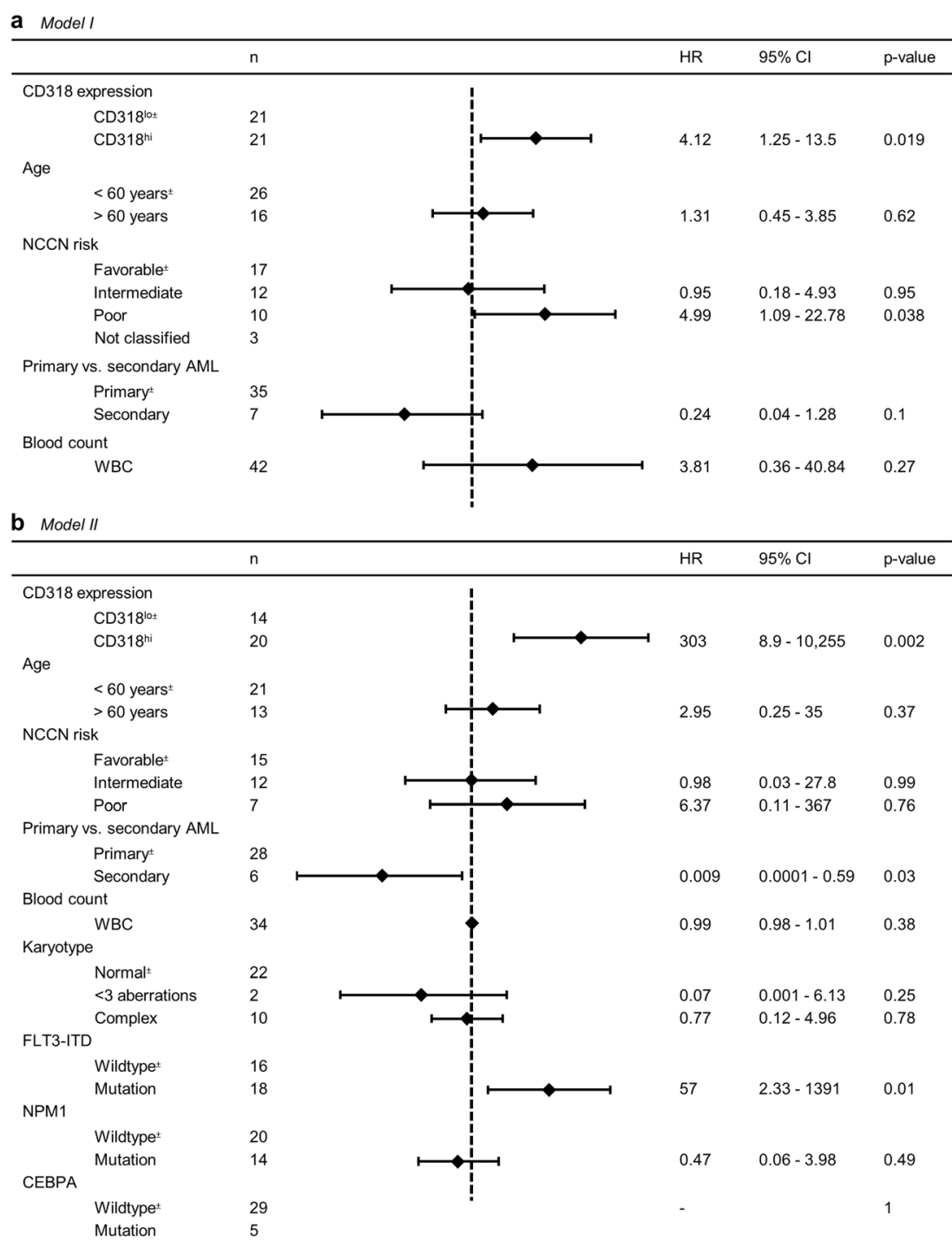

Moreover, we were not able to detect a significant difference between $\mathrm{CD} 318^{\mathrm{lo}}$ and $\mathrm{CD} 318^{\text {hi }}$ AML cases with regard to OS when we did not discriminate with regard to the applied treatment strategy. However, when we grouped our patients according to the applied treatment, we found that patients receiving intense AML treatment and expressing low levels of CD318 on AML blasts had significantly longer OS and a tendency to longer PFS. On the contrary, $\mathrm{CD} 318^{\text {hi }}$ cases receiving best available alternative therapy showed increased survival.

Upon more detailed analysis, we identified 13 patients receiving hypomethylating agents as initial AML treatment. In this small group, there was a trend towards better OS with CD318 expression. Of note, CD318 expression reportedly is highly variable in other tumors and depends on DNA methylation of its promotor region $[23,29]$. It has been reported that AML blasts are dependent on promoter methylation of tumor suppressor genes [30], which is inhibited by hypomethylating agents (e.g., decitabine) [31]. It is tempting to speculate that high expression of CD318 could be used as marker for the degree of DNA methylation in AML, and this issue should be addressed in future studies, as we were not able to analyze changes of CD318 surface expression upon treatment due to lack of respective patient samples.

If CD318 expression would be stable upon therapy, the CD318 ${ }^{\text {hi }}$ AML patient population would potentially benefit from a combinational treatment with an anti-CD318 antibody, such as RG7287 (humanized CD318 antibody). This is based on observations that in vivo xenograft testing with a breast cancer cell line showed therapeutic potential of this antibody in combination with paclitaxel, with inhibition of metastasis being the most impressive read out [32].

In conclusion, to our knowledge, this is the first analysis of CD318 surface levels on leukemic cells in a larger cohort of AML patients. The observed association of CD318 expression with OS in patients receiving anthracycline-based induction therapy or best available alternative therapy points the suitability of CD318 analysis as prognostic marker and indicates that CD318 might serve as target antigen for immunotherapeutic approaches. 
Acknowledgments The authors thank Valentina Agrusa for expert technical assistance.

Author contributions HRS, MM, JK, and JSH designed the research. $\mathrm{JSH}, \mathrm{IH}$, and $\mathrm{JK}$ performed and analyzed flow cytometry experiments. $\mathrm{MR}$, JSH, and $\mathrm{CH}$ collected blood samples and clinical data. JSH and $\mathrm{CH}$ performed statistical analyses. JK, JSH, and MM wrote the manuscript. HRS and GJ provided important research advice and revised the manuscript. All coauthors read and accepted the manuscript.

Funding information Open Access funding provided by Projekt DEAL. This work was supported by grants from Deutsche Forschungsgemeinschaft (SA1360/9-1 and SA1360/7-3), Wilhelm Sander-Stiftung (2007.115.3), Deutsche Krebshilfe (111828, 70113496, and 70112914), and Germany's Excellence Strategy (EXC 2180/1).

\section{Compliance with ethical standards}

Conflict of interests The authors declare that they have no conflict of interests.

Ethical approval All procedures performed in studies involving human participants were in accordance with the ethical standards of the institutional research committee (Committee of the University of Tübingen vote $13 / 2007 \mathrm{~V}$ ) and with the 1964 Helsinki declaration and its later amendments or comparable ethical standards. This article does not contain any studies with animals performed by any of the authors.

Informed consent Informed consent was obtained from all individuals included in the study.

Open Access This article is licensed under a Creative Commons Attribution 4.0 International License, which permits use, sharing, adaptation, distribution and reproduction in any medium or format, as long as you give appropriate credit to the original author(s) and the source, provide a link to the Creative Commons licence, and indicate if changes were made. The images or other third party material in this article are included in the article's Creative Commons licence, unless indicated otherwise in a credit line to the material. If material is not included in the article's Creative Commons licence and your intended use is not permitted by statutory regulation or exceeds the permitted use, you will need to obtain permission directly from the copyright holder. To view a copy of this licence, visit http://creativecommons.org/licenses/by/4.0/.

\section{References}

1. Dohner H, Estey E, Grimwade D, Amadori S, Appelbaum FR, Buchner T, Dombret H, Ebert BL, Fenaux P, Larson RA, Levine RL, Lo-Coco F, Naoe T, Niederwieser D, Ossenkoppele GJ, Sanz M, Sierra J, Tallman MS, Tien HF, Wei AH, Lowenberg B, Bloomfield CD (2017) Diagnosis and management of AML in adults: 2017 ELN recommendations from an international expert panel. Blood 129(4):424-447. https://doi.org/10.1182/blood-201608-733196

2. Estey EH (2018) Acute myeloid leukemia: 2019 update on riskstratification and management. Am J Hematol 93(10):1267-1291. https://doi.org/10.1002/ajh.25214

3. De Kouchkovsky I, Abdul-Hay M (2016) Acute myeloid leukemia: a comprehensive review and 2016 update. Blood Cancer J 6(7): e441. https://doi.org/10.1038/bcj.2016.50
4. Hooper JD, Zijlstra A, Aimes RT, Liang H, Claassen GF, Tarin D, Testa JE, Quigley JP (2003) Subtractive immunization using highly metastatic human tumor cells identifies SIMA135/CDCP1, a $135 \mathrm{kDa}$ cell surface phosphorylated glycoprotein antigen. Oncogene 22(12): 1783

5. Bühring HJ, Kuçi S, Conze T, Rathke G, Bartolović K, Grünebach F, Scherl-Mostageer M, Brümmendorf TH, Schweifer N, Lammers R (2004) CDCP1 identifies a broad spectrum of normal and malignant stem/progenitor cell subsets of hematopoietic and nonhematopoietic origin. Stem Cells 22(3):334-343

6. Conze T, Lammers R, KuÇi S, Scherl-Mostageer M, Schweifer N, Kanz L, Bühring HJ (2003) CDCP1 is a novel marker for hematopoietic stem cells. Ann N Y Acad Sci 996(1):222-226

7. Enyindah-Asonye G, Li Y, Ruth JH, Spassov DS, Hebron KE, Zijlstra A, Moasser MM, Wang B, Singer NG, Cui H (2017) CD318 is a ligand for CD6. Proc Natl Acad Sci 114(33):E6912E6921

8. Perry SE, Robinson P, Melcher A, Quirke P, Bühring H-J, Cook GP, Blair GE (2007) Expression of the CUB domain containing protein 1 (CDCP1) gene in colorectal tumour cells. FEBS Lett 581(6): $1137-1142$

9. Ji I, Oda T, Inoue M, Uekita T, Sakai R, Okumura M, Aozasa K, Morii E (2009) Expression of CUB domain containing protein (CDCP1) is correlated with prognosis and survival of patients with adenocarcinoma of lung. Cancer Sci 100(3):429-433

10. Scherl-Mostageer M, Sommergruber W, Abseher R, Hauptmann R, Ambros P, Schweifer N (2001) Identification of a novel gene, $\mathrm{CDCP} 1$, overexpressed in human colorectal cancer. Oncogene 20(32):4402-4408

11. Awakura Y, Nakamura E, Takahashi T, Kotani H, Mikami Y, Kadowaki T, Myoumoto A, Akiyama H, Ito N, Kamoto T (2008) Microarray-based identification of CUB-domain containing protein 1 as a potential prognostic marker in conventional renal cell carcinoma. J Cancer Res Clin Oncol 134(12):1363-1369

12. Cao M, Gao J, Zhou H, Huang J, You A, Guo Z, Fang F, Zhang W, Song T, Zhang T (2016) HIF-2 $\alpha$ regulates CDCP1 to promote PKC $\delta$-mediated migration in hepatocellular carcinoma. Tumor Biol 37(2): 1651-1662

13. Miyazawa Y, Uekita T, Hiraoka N, Fujii S, Kosuge T, Kanai Y, Nojima Y, Sakai R (2010) CUB domain-containing protein 1, a prognostic factor for human pancreatic cancers, promotes cell migration and extracellular matrix degradation. Cancer Res 70(12): 5136-5146

14. Alajati A, Guccini I, Pinton S, Garcia-Escudero R, Bernasocchi T, Sarti M, Montani E, Rinaldi A, Montemurro F, Catapano C (2015) Interaction of CDCP1 with HER2 enhances HER2-driven tumorigenesis and promotes trastuzumab resistance in breast cancer. Cell Rep 11(4):564-576

15. Casar B, Rimann I, Kato H, Shattil S, Quigley J, Deryugina E (2014) In vivo cleaved CDCP1 promotes early tumor dissemination via complexing with activated $\beta 1$ integrin and induction of FAK/ PI3K/Akt motility signaling. Oncogene 33(2):255-268

16. Casar B, He Y, Iconomou M, Hooper JD, Quigley JP, Deryugina EI (2012) Blocking of CDCP1 cleavage in vivo prevents Aktdependent survival and inhibits metastatic colonization through PARP1-mediated apoptosis of cancer cells. Oncogene 31(35): 3924-3938

17. Deryugina EI, Conn EM, Wortmann A, Partridge JJ, Kupriyanova TA, Ardi VC, Hooper JD, Quigley JP (2009) Functional role of cell surface CUB domain-containing protein 1 in tumor cell dissemination. Mol Cancer Res 7(8):1197-1211

18. Uekita T, Fujii S, Miyazawa Y, Iwakawa R, Narisawa-Saito M, Nakashima K, Tsuta K, Tsuda H, Kiyono T, Yokota J (2014) Oncogenic Ras/ERK signaling activates CDCP1 to promote tumor invasion and metastasis. Mol Cancer Res 12(10):1449-1459 
19. Bennett JM, Catovsky D, Daniel MT, Flandrin G, Galton DA, Gralnick HR, Sultan C (1985) Proposed revised criteria for the classification of acute myeloid leukemia: a report of the FrenchAmerican-British Cooperative Group. Ann Intern Med 103(4): $620-625$

20. Bennett JM, Catovsky D, Daniel MT, Flandrin G, Galton DA, Gralnick HR, Sultan C (1976) Proposals for the classification of the acute leukaemias French-American-British (FAB) Co-operative Group. Br J Haematol 33(4):451-458

21. O'Donnell MR, Tallman MS, Abboud CN, Altman JK, Appelbaum FR, Arber DA, Bhatt V, Bixby D, Blum W, Coutre SE (2017) Acute myeloid leukemia, version 3.2017, NCCN clinical practice guidelines in oncology. J Natl Compr Cancer Netw 15(7):926-957

22. Dohner H, Estey EH, Amadori S, Appelbaum FR, Buchner T, Burnett AK, Dombret H, Fenaux P, Grimwade D, Larson RA, Lo-Coco F, Naoe T, Niederwieser D, Ossenkoppele GJ, Sanz MA, Sierra J, Tallman MS, Lowenberg B, Bloomfield CD, European L (2010) Diagnosis and management of acute myeloid leukemia in adults: recommendations from an international expert panel, on behalf of the European LeukemiaNet. Blood 115(3):453474

23. Ji I, Morii E, Kimura H, Tomita Y, Takakuwa T, Ji H, Kim YK, Miyoshi Y, Noguchi S, Nishida T (2006) Epigenetic regulation of the expression of the novel stem cell marker CDCP1 in cancer cells. J Pathol 210(1):75-84

24. Takeda H, Fujimori Y, Kai S, Ogawa H, Nakano T (2010) CD318/ CUB-domain-containing protein 1 expression on cord blood hematopoietic progenitors. Experimental therapeutic Medicine 1(3):497501

25. Emerling BM, Benes CH, Poulogiannis G, Bell EL, Courtney K, Liu H, Choo-Wing R, Bellinger G, Tsukazawa KS, Brown V (2013) Identification of CDCP1 as a hypoxia-inducible factor $2 \alpha$ $(\mathrm{HIF}-2 \alpha)$ target gene that is associated with survival in clear cell renal cell carcinoma patients. Proc Natl Acad Sci 110(9):34833488
26. Rouault-Pierre K, Lopez-Onieva L, Foster K, Anjos-Afonso F, Lamrissi-Garcia I, Serrano-Sanchez M, Mitter R, Ivanovic Z, de Verneuil H, Gribben J (2013) HIF-2 $\alpha$ protects human hematopoietic stem/progenitors and acute myeloid leukemic cells from apoptosis induced by endoplasmic reticulum stress. Cell Stem Cell 13(5):549-563

27. Forristal C, Brown A, Helwani F, Winkler I, Nowlan B, Barbier V, Powell R, Engler G, Diakiw S, Zannettino A (2015) Hypoxia inducible factor (HIF)- $2 \alpha$ accelerates disease progression in mouse models of leukemia and lymphoma but is not a poor prognosis factor in human AML. Leukemia 29(10):2075

28. Kollmorgen G, Niederfellner G, Lifke A, Spohn GJ, Rieder N, Vega Harring S, Bauss F, Burtscher H, Lammers R, Bossenmaier B (2013) Antibody mediated CDCP1 degradation as mode of action for cancer targeted therapy. Mol Oncol 7(6):1142-1151

29. Kimura H, Morii E, Ikeda J, Ezoe S, Xu J, Nakamichi N, Tomita Y, Shibayama H, Kanakura Y, Aozasa K (2006) Role of DNA methylation for expression of novel stem cell marker CDCP1 in hematopoietic cells. Leukemia 20(9):1551-1556

30. Herman JG, Baylin SB (2003) Gene silencing in cancer in association with promoter hypermethylation. N Engl J Med 349(21): 2042-2054. https://doi.org/10.1056/NEJMra023075

31. Covey JM, D'Incalci M, Tilchen EJ, Zaharko DS, Kohn KW (1986) Differences in DNA damage produced by incorporation of 5-aza-2'deoxycytidine or 5,6-dihydro-5-azacytidine into DNA of mammalian cells. Cancer Res 46(11):5511-5517

32. Kollmorgen G, Lifke A, Nopora A, Bauss F, Niederfellner G, Bossenmaier B (2014) RG7287, a novel humanized anti-CDCP1 antibody with superior preclinical in vivo efficacy in combination with paclitaxel. Mol Oncol 7(6):1142-1151

Publisher's note Springer Nature remains neutral with regard to jurisdictional claims in published maps and institutional affiliations. 